\title{
Support Workers and Nursing Associates as Coaches
}

David Stonehouse is a Lecturer in Children and Young People's Nursing with the School of Health and Society at the University of Salford, Manchester.

\section{Abstract.}

This article examines the important role that support workers and nursing associates play in being a coach for other less experienced team members. There is a difference between being a coach and being a mentor and this will be explored. The requirement to be a coach are laid down in both The Code of Conduct for Healthcare Support Workers and Adult Social Care Workers in England (Skills for Care and Skills for Health, 2013) and for nursing associates in the recently amended NMC (2018) code. Relevant sections of these two codes will be highlighted. The article will then move on to discuss the importance of planning in advance so that the best support and development can be attained. Reflection at the end by both the coach and learner is key.

Key Words: Coaching, Development, Mentoring, Nursing Associates, Support Workers, Training.

\section{$\underline{\text { Introduction }}$}

Support workers and those moving into nursing associate roles are often very experienced professionals with an extensive range of skills and knowledge gained and developed over a number of years. This knowledge and experience needs to be shared with other more junior members of the team. One way that this can be achieved is through coaching.

\section{Coaching or Mentoring?}

Often when we think of a coach we picture someone in charge of a sports team with a number of players. However, as Marquis and Huston (2017:425) state it is often more "one person helping the other to reach an optimum level of performance." They go on to state that coaching can either be short or long term. "Short-term coaching is effective as a teaching tool, for assisting with socialisation, and for dealing with shortterm problems" (Marquis \& Huston, 2017:426). When it is more of a long-term relationship, Thompson (2013:183) states the teaching may develop into more a mentoring role than coaching, with the "relationship geared towards learning and development more generally." Mullins (2013) identifies the difference between 
coaching and mentoring. Coaching is a "supportive relationship aimed at creating understanding, direction and action" helping a person to move forwards, whereas mentoring is where an expert offers guidance, support and advice (Mullins, 2013:193).

Coaching can also occur after a more formal training course has taken place. The training course will be aimed at teaching a group of people at the same time, meeting the needs of the group as a whole. Once the course has finished the coach could then meet with the individual learner and help to consolidate the learning they have received, addressing any specific issues, or focusing upon any unmet individual needs they may have (Thompson, 2013).

\section{Code Words.}

Both, The Code of Conduct for Healthcare Support Workers and Adult Social Care Workers in England (Skills for Care and Skills for Health, 2013), and the NMC (2018) Code, both encourage and entreat the support worker and nursing associate to take on a coaching role. First of all, in section 3.1 the Code for support workers gives you a clear call to "understand and value your contribution and the vital part you play in your team." Once you embrace this truth will you be empowered to coach others in the experience and knowledge you have. In section 6.6 it goes on to state you must "contribute to the learning and development of others as appropriate." Clearly setting coaching out as part of your role. Section 6 where this subsection sits, is focused upon you striving to "improve the quality of healthcare, care and support through continuing professional development.

The NMC (2018) code for nurses, midwives and nursing associates states in Section 9 that you must "share your skills, knowledge and experience for the benefit of people receiving care and your colleagues." To achieve this, it states in 9.1 that you must "provide honest, accurate and constructive feedback to colleagues," and in 9.4 that you must 'support students' and colleagues' learning to help them develop their professional competence and confidence." Therefore, it is made very clear that both support workers and nursing associates need to embrace the role of the coach within their clinical practice.

\section{Preparation}

Coaching can often be something that happens spontaneously as an opportunity presents itself. You may be working alongside someone and it just naturally occurs. These coaching opportunities must not be missed. When this happens there may not be time to plan ahead. However, through identifying areas where coaching is required, forward planning can then be performed, allowing you to facilitate the best learning and development opportunities. 


\section{$\underline{\text { Consent }}$}

If the coaching session involves a patient and or carer, then you will need to gain their consent. You will need to explain exactly what is going to happen and why. Explain that you are an experienced member of staff and that you are going to coach another member of the team in how to perform this task or procedure. State that you will be supervising any care given. Give them time to ask any questions they may have. Only when the patient and or their carer is happy and have given their informed consent may you proceed (Stonehouse, 2011). It is completely within their rights to say no and refuse.

\section{Objectives and Learning Outcomes}

You need to identify what it is you are wanting the learner to achieve by the end of the session. What new knowledge or skill do you want them to have learnt? It may be an increased awareness of the importance of something, or the ability to perform a certain task safely. Having objectives and learning outcomes allows you at the end of the session to re-visit these, to assess have these been achieved making the coaching session a success or not.

\section{Lesson Planning}

Once you have identified the learning outcomes and objectives of the session, you then need to formulate a plan as to how you are going to achieve this. This is your lesson plan. Basically, it is an outline of how you are going to facilitate this learning opportunity. It could be as simple as starting with an introduction to the task. Then moving on to state why the task is important and anything that needs to be considered. Following this a demonstration of the task by the coach. Answer any questions as they arise. Then ask the learner to perform the task under your supervision. At the end conclude by highlighting any main points or things to take forward, clarifying any outstanding points.

\section{Resources Needed.}

When planning a coaching session one of the things you need to consider is what if any equipment you will need. The resource may actually be the patient themselves. However other resources could be clinical equipment, visual aids, handouts or even video clips. These need to be prepared before the session starts.

\section{Location and Environment}

Consider where the coaching session is going to take place. It could be at the patient's bedside or in their own home. It could be in the treatment room, or staff room/office. Have you enough physical space to perform the skill or procedure you are teaching. You may need to re-arrange the environment. If in a patient's home remember to put everything back again afterwards. Do you need chairs and tables or other pieces of furniture to use within the session? Is this something to be done 
indoors or outdoors? If outdoors consider clothing and footwear of everyone involved. Is there enough light to see properly in the area. Are there distractions present which could interfere with the learning? This could be other people wandering around or watching, or excessive noise. Do you need to go somewhere quieter and more private?

\section{Assessment of Learners Understanding.}

You also need to consider how you are going to assess the learners understanding and possible competence at doing this new skill or task. This could be through asking the learner to demonstrate what has been shown. Or through asking questions either at the end or as you go along. Do not be disappointed if you find that the learner needs more support moving forwards, as more complex procedures may need more on going coaching and supervision.

\section{$\underline{\text { Reflection }}$}

Afterwards, it is very important to reflect upon how the coaching session went. Did the session go to plan? Could you have done anything differently to improve it? Ask the learner to give you feedback as well. What was it like from their point of view? Do they feel that you went at the correct speed and did not rush through any parts of it? Only by reflecting from both points of view, will you be able to develop your coaching skills for the next time.

\section{Conclusion.}

So to conclude, this article has highlighted the important role that support workers and nursing associates have in coaching more junior or less experienced members of the team. This role is supported by both the support workers Code (Skills for Care and Skills for Health, 2013), and the Code for nursing associates (NMC, 2018). Coaching can occur on the spur of the moment taking advantage of opportunities as they present themselves. However, coaching can also be planned for when time allows. When this is the case the process can be thought through identifying learning outcomes, resources required, environment and how the acquisition of new knowledge by the learner can be assessed. Through embracing this important part of their role, support workers and nursing associates can pass on their extensive knowledge and skills, developing their colleagues and ultimately facilitating the delivery of high quality care.

\section{Key Points:}

1. Support workers are extremely knowledgeable experts in their own practice.

2. Therefore, they need to embrace the coaching role in developing new and less experienced team members. 
3. Coaching can happen both on the spur of the moment or be planned in advance.

4. Consent needs to be gained where patient and carer involvement is required.

5. Reflecting back on the process by both the learner and the coach is important.

\section{$\underline{\text { Reflective Questions for Your Continuing Professional Development }}$}

- Identify one skill or task that you perform which you could teach to a new member of staff.

- What resources would you need, where would be the best place to teach it?

- Write a lesson plan outlining how you would teach this skill or task, identifying learning objectives and how you would check the learners understanding.

- Now deliver your coaching session, and afterwards reflect upon how it went. Ask the learner to provide feedback as well.

\section{References:}

Marquis BL, Huston CJ. Leadership Roles and Management Functions in Nursing: Theory and Application. 9 ${ }^{\text {th }}$ edn. China: Wolters Kluwer; 2017

Mullins LJ. Management and Organisational Behaviour. $10^{\text {th }}$ edn. Harlow: Pearson Education Ltd; 2013

Nursing and Midwifery Council. The Code: Professional Standards of Practice and Behaviour for Nurses, Midwives and Nursing associates. 2018.

https://www.nmc.org.uk/globalassets/sitedocuments/nmc-publications/nmc-code.pdf (accessed 7 December 2018)

Skills for Care and Skills for Health. Code of Conduct for Healthcare Support Workers and Adult Social Care Workers in England. 2013. http://www.skillsforhealth.org.uk/images/services/code-ofconduct/Code\%20of\%20Conduct\%20Healthcare\%20Support.pdf (accessed 7 December 2018)

Stonehouse D. Gaining consent and protecting the rights of patients. British Journal of Healthcare Assistants. 2011; 5(9): 457-458

Thompson N. People Management. London: Palgrave Macmillan; 2013 